\title{
A METODOLOGIA DA HISTÓRIA EM REINHART KOSELLECK: ANÁLISE E APLICAÇÃO À PESQUISA JURÍDICA
}

\section{LA METODOLOGÍA DE LA HISTORIA EN REINHART KOSELLECK: ANÁLISIS Y APLICACIÓN A LA INVESTIGACIÓN JURÍDICA}

\author{
${ }^{1}$ Roland Hamilton Marquardt Neto
}

\section{RESUMO}

Os desafios e dificuldades da condução da pesquisa acadêmica, bem como a qualidade do resultado do seu objeto de investigação, depende, invariavelmente, na opção da metodologia empregada. Nesse sentido, impõe-se cada vez mais estudar os variados métodos de pesquisa, independentemente da área circunspecta ao pesquisador, uma vez que está em voga a interdisciplinaridade na pesquisa jurídica. No entanto, adverte-se que a interdisciplinaridade impõe uma redobrada atenção e cuidado na análise científica, uma vez que aumentada a complexidade nas escolhas de condução metodológica de um trabalho acadêmico, podendo, se não, subverter o objeto perquirido. Nesse diapasão, propõe-se analisar a metodologia da história apresentada por Reinhart Koselleck, de modo que se possa apontar em que medida seus métodos possam contribuir a uma pesquisa atinente às áreas jurídicas dogmática ou zetética. Nessa moldura, constata-se que tanto Histórica, quanto à História dos Conceitos, ambos os métodos originários dos estudos de Kosseleck, podem imprimir um rico aporte teórico na pesquisa jurídica, na medida que permita eliminar a plurissignificação de conceitos, classificá-los, relacioná-los, até mesmo ordenar pensamentos, conferindo-lhes certa conotação de durabilidade; bem como permitir a compreensão histórica e antropológica do progresso da modernidade, reconhecendo a (des)continuidade das estruturas em determinado contexto social e temporal. Portanto, tem-se diante dessa proposta a justificativa em estudar os métodos históricos de Reinhart Koselleck, não como pretensão de apontar-se a solução universal de como conduzir uma pesquisa jurídica, mas sim como apresentação à Academia de um método fértil na investigação científica.

Palavras-chave: Reinhart koselleck, Metodologia científica, Filosofia da história, História dos conceitos, História do direito

\footnotetext{
${ }^{1}$ Mestrando em Direito na Universidade Federal do Rio Grande do Sul - UFRGS, Porto Alegre - RS (Brasil). Email: roland.marquardt@hotmail.com
} 


\section{RESUMEN}

Los desafíos y las dificultades de la realización de la investigación académica, así como la calidad del resultado de su objeto de investigación depende, invariablemente, de la elección de la metodología empleada. En este sentido, se insta cada vez más estudiar los diversos métodos de investigación, independetemiente, de la zona perspicaz de lo investigador, ya que está en boga la interdisciplinariedad de la investigación jurídica. Sin embargo, se advierte que la interdisciplinariedad requiere atención cuidadosa y el análisis científico cuidadosa, ya que aumenta la complejidad en la conducción de las elecciones metodológicas de un trabajo académico, pudendo, si no, subvertir el objeto perquirido. En este sentido, se propone analizar la metodología de la historia presentada por Reinhart Koselleck, de modo que si pueda señalar en qué medida sus métodos pueden contribuir a una investigación referente a las áreas jurídicas - dogmática o zetética. En este marco, parece que tanto la Histórica, asó como la "Historia de los conceptos", ambos métodos originarios de estudios Kosseleck, pueden imprimir un rico soporte teórico a la investigación jurídica, en la medida en que puede eliminar los plurissignificativos conceptos, los clasificar y relacionar, até mismo ordenar pensamientos, dándoles una cierta connotación de durabilidad; así como permitir la comprensión histórica y antropológica de los avanzos de la modernidad, reconociendo la (dis) continuidad de las estructuras de un contexto social determinado y en el tiempo. Por lo tanto, ha sido en esta propuesta, la justificación en el estudio de los métodos históricos de Reinhart Koselleck, pero no con una pretensión de apuntar a una solución universal apta a llevar a cabo la investigación jurídica, sino como una presentación ante la Academia de un método fértil en la investigación científica.

Palabras-claves: Reinhart koselleck, metodología científica, filosofía de la historia, historia de los conceptos, Historia del derecho 


\section{INTRODUÇÃO}

A Metodologia está para pesquisa acadêmica como um mastro está para um barco, na medida que é o instrumento indispensável à condução segura no vasto campo do saber. Tal premissa sempre pautou a pesquisa científica, inclusive se confundindo com um pleonasmo, já que é sabido que não há ciência sem pesquisa, como não há pesquisa sem o emprego metodológico. Veja que o método em si, apropriando-se da mesma figura de linguagem, é a vela que acomoda o mastro, devendo esta ser adaptada conforme os rigores e desafios que devem ser suportados.

Assim, faz-se mister compreender, seja o pesquisador de qualquer área, as variadas gamas de métodos para a pesquisa, de modo que se torne possível escolher a proposta metodológica oportuna, que conduza a descoberta científica almejada.

Nesse diapasão, o presente artigo propõe analisar, detidamente, a solução metodológica de pesquisa histórica apresentada por Reinhart Koselleck, natural da cidade de Gorlitz - Alemanha, professor de História das Universidades de Bochum (1966 - 1968), Heidelberg (1968 - 1973) e Bielefeld $(1973 \text { - 1988) })^{1}$. Ressalta-se que a pertinência do estudo das lições de Koselleck, repousa na profundidade de suas reflexões sobre a pesquisa histórica, que impulsionou debates a diversos ramos das Ciências, inclusive a Jurídica. Ainda sobre Koselleck, importante registrar que se tornou referência no marco teórico da historiografiagermânica pós Segunda Guerra Mundial, responsável por uma vasta produção de obras na área da filosofia e metodologia da história, destacando-se as obras: Crítica e Crise (Kritik und Krise); Futuro Passado: Contribuição à Semântica dos Tempos Históricos (Vergangene Zukunft: Zur Semantik geschichtlicher Zeiten) e História dos Conceitos (Begriffsgeschichte).

Não obstante, registra-se que não apenas buscar-se-á apresentar a proposta metodológica de pesquisa histórica koselleckiana, como também se propõem conjectura-la à pesquisa jurídica, de modo que se possa evidenciar a possibilidade de emprego desse método na investigação de objetos característicos do Direito.

\footnotetext{
${ }^{1}$ Para uma análise biográfica completa de Reinhart Koselleck, recomenda-se a leitura da obra "History in the Plural: an introduction to the work of Reinhart Koselleck”, do autor escandinavo Niclkas Olsen.
} 


\title{
2. O MÉTODO KOSELLECKIANO DE PESQUISA DA HISTÓRIA: DA "HISTÓRICA" (HISTORIKE) À (BEGRIFFSGESCHICHTE) "HISTÓRIA DOS CONCEITOS"
}

\subsection{A Metodologia como norte da pesquisa científica}

Inicialmente, devemos compreender a justificativa que permeia todo o estudo proposto neste artigo, ou seja, responder a pergunta que ainda é, consideravelmente, negligenciada em setores acadêmicos no Brasil²: Por quê e para quê estudar metodologia?

Não se olvida que o estudo da metodologia é indispensável para uma melhor orientação epistemológica de um trabalho científico, pois, emprestando-se a lição de Eduardo Bittar (2011, p. 17), a pesquisa científica é, em si, um método correspondente ao planejamento de recursos, técnicas e meios de investigar determinado objeto, concluindo-se que, "o trabalho científico deverá ser um todo articulado e logicamente concatenado”.

Quanto à importância da aplicação do método na pesquisa acadêmica, ressalta que:

\begin{abstract}
O universo do conhecimento é irrestrito. Ademais, suas fronteiras são sempre expansíveis. Por isso, a produção do conhecimento se faz sempre dentro de pretensões limitadas e por especialidades. É impossível tudo conhecer, de modo que a pretensão do conhecimento deve obedecer a busca metodologicamente guiadas. O método, nesse sentido, oferece a vantagem de fornecer uma perspectiva para que se enxergue a realidade e, ao reduzir o foco projetada sobre ela, confere segurança ao percurso investigativo. (BITTAR, 2011, p. 17),
\end{abstract}

Ainda, quanto ao emprego do método na pesquisa científica, D’Onofrio (apud BITTAR, p. 30) traça, com brilhantismo, o seguinte paralelo:

Mas existe algo em comum que deve amalgamar todas essas linguagens, distinguindo a atividade verdadeiramente intelectual do charlatanismo: a seriedade da pesquisa, a busca da verdade, a honestidade profissional, a coerência metodológica, a indignação perante a mentira, a injustiça, a tirania, o estímulo à reflexão sobre a vida na natureza e em sociedade com a intenção de melhorar o convívio entre os homens.

\footnotetext{
2 Diante desse quadro cultural, todos os anos, a academia jurídica brasileira perde conteúdo de cientificidade em suas monografias (latu sensu) e artigos, mormente, diante da negligência à metodologia da pesquisa e ao preconceito da interdisciplinaridade. Nesse sentido, Bittar (2011, p. 36) sentencia que: "Enquanto isso, os estudos de caso, a jurisprudência comparada, a pesquisa empírico-sociológica, a discussão do debate hermenêutico, a historiografia dos fatos jurídico-políticos, os estudos da aplicação das penas, a criminologia empírica, as implicações ético-profissionais das práticas jurídicas, os estudos processuais de inclusão social pelo acesso à justiça em regiões periféricas de grandes centros urbanos e regiões metropolitanas, as tramas do raciocínio decisório, as pesquisas de politologia jurídica, a arqueologia dos projetos de lei, os estudos estatísticos das tendências do Judiciário, o levantamento de documentos históricos referentes aos episódios de forte significação para o sistema jurídico brasileiro, são todas questões relegadas ao esquecimento, ou a uma notoriedade tão opaca que seja incapaz de extravasar o âmbito das academias de ensino do direito".
} 
Também, tem-se elucidativa a lição de Jovilet (apud BITTAR, 2011, p. 30) ao explicar que: "O método tem como fim disciplinar o espírito, excluir de suas investigações o capricho e o acaso, adaptar o esforço a empregar segundo as exigências do objeto, determinar os meios de investigação e a ordem da pesquisa. Ele é, pois, fator de segurança e economia”.

Quanto à classificação da metodologia no campo do saber, muito se discute sobre a sua natureza, se é disciplina, teoria da ciência ou Ciência autônoma. Nesse celeuma, Bittar esclarece o que não é metodologia em quatro pontos: $1^{\circ}$ - não se reduz a mero estudo da tecnologia acerca das práticas científicas; $2^{\circ}$ não se confunde com filosofia e epistemologia; $3^{\circ}$ não representa a mesma lógica da ciência; $4^{\circ}$ não é lógica do raciocínio, nem parte da lógica (Ibid, 2011, p. 17).

Sem embargo, vislumbrado os pontos que não categorizam a metodologia, Bittar (2011, p. 43-44) passa analisar o que congrega positivamente o estudo da metodologia:

\begin{abstract}
Assim, entenda-se que a metodologia consiste numa paxiologia, ou seja, estudo propõe reflexão sobre as práticas científicas de pesquisa e sobre o processo de criação científica, e isso porque: 1) propõe o conhecimento sobre meios, técnicas e fins em pesquisa, facilitando a consciência sobre os processos de criação e pesquisa; 2) favorece e estimula a dispersão adequada de ideias, propondo os meios para tanto; 3) discute critérios e métodos, assim como confere suporte reflexivo à regulamentação normativa das práticas cientificas; 4) desmistifica o estatuto do saber científico, desnudado as formas de alcança-lo; diferindo-o também de outros saberes; 5) fortalece o conhecimento da forma, entendida esta como a adequada maneira da divulgação de conhecimentos, e erige o rigor como condição não suficiente para o fazer científico; 6) identifica os meios de recolhimento, tratamento e divulgação de informações; 7) separa, identifica e organiza conhecimentos de interesse para a construção da pesquisa; 8) eleva a importância do discurso como forma de prática do saber e divulgação de resultados de pesquisa.
\end{abstract}

Ainda, por conta da definição de pesquisa científica, válido o registro de Álvaro Viera Pinto (apud BITTAR, 2011, p. 21):

\begin{abstract}
A pesquisa científica é um aspecto, na verdade o momento culminante, de um processo de extrema amplitude e complexidade pelo qual o homem realiza sua suprema possibilidade existencial, aquela que dá conteúdo à sua essência de animal que conquistou a racionalidade: a possibilidade de dominar a natureza, transformá-la, adaptá-la às suas necessidades. Este processo chama-se conhecimento.
\end{abstract}

Desse modo, conclui-se que, para evitar que a pesquisa científica seja apenas um mero levantamento de dados e de especulações, faz-se necessário uma criteriosa escolha de métodos, filtragens e tratamento de informação, para perquirir o objeto de estudo.

Nessa moldura, oportuno a lição de Pedro Demo em sua "Introdução à metodologia da Ciência” (apud BITTAR, 2011, p. 41): 
Metodologia é uma preocupação instrumental. Trata das formas de se fazer ciência. Cuida dos procedimentos, das ferramentas, dos caminhos. A finalidade da ciência é tratar a realidade teórica e pratica. Para Atingirmos tal finalidade, colocam-se vários caminhos. Disto trata a metodologia.

No que tange aos objetivos da metodologia, Bruyne, Herman e Schoutheete (apud BITTAR, p. 41) ensinam que:

\begin{abstract}
O objetivo da metodologia, que é uma paxiológica da produção dos objetos científicos, é o de esclarecer a unidade subjacente a uma multiplicidade de procedimentos científicos particulares, ela ajuda a desimpedir os caminhos da prática concreta da pesquisa dos obstáculos que esta encontra.
\end{abstract}

Veja-se então, que a metodologia se apresenta como condição indispensável à pesquisa, seja ela de qualquer ciência, das exatas às humanas. Ademais, registra-se que por meio da adoção do método, como instrumento de investigação científica, que se trona possível absolver o trabalho da opinião subjetiva do investigador (Ibid, 2011, p. 30).

Dessarte, superado a pertinência e justificativa do estudo da metodologia, sublinha-se que, antes de analisarmos a proposta metodológica koselleckiana, faz-se necessário observarmos o contexto histórico por qual a metodologia da História e, especificamente, da História do Direito se inseria, quando Reinhart Koselleck concebeu suas obras chaves, que são: Crítica e Crise (Kritik und Krise), Futuro Passado: Contribuição à Semântica dos Tempos Históricos (Vergangene Zukunft: Zur Semantik geschichtlicher Zeiten) e História dos Conceitos (Begriffsgeschichte).

\title{
2.2 A Transformação do Estudo da História no Século XX: A Primazia Metodológica da História Geral em Detrimento das Histórias Particulares
}

A transformação do estudo da História, de modo que hoje se as tendências metodológicas atuais são substancialmente diversa do século XIX e XX. Naquele período, conforme leciona Pietro Costa (2010, p. 18) o pesquisador buscava descrever "a grande narrativa do discurso global sobre o homem e as suas relações intersubjetivas”. Assim, a proposta metodológica para tal mister era essencialmente corolário teórico do positivismo, neoidealismo e marxismo. 
No entanto, diante da recorrente falha metodológica para que que vislumbrasse um seguro diagnóstico das crises da atualidade, aqueles modelos teóricos foram sendo substituídos por premissas que permitissem uma interpretação do s fatos, e não mera descrição.

Nessa senda, Pietro Costa (2010, p. 20-21) registra, atualmente, a primazia metodológica de uma história geral em detrimento de histórias particulares, sendo que aquelas, diversamente de uma análise estritamente particular e secundária das histórias, buscam: “

a) alcançar uma compreensão tendencialmente global da realidade do passado; b) individualizar, dentro da sociedade do passado, tipos de ações, níveis de realidade, mais relevantes que outras com respeito ao funcionamento global da sociedade mesma; c) estabelecer, por consequências, internamente à historiografia, alguma hierarquia "epistemológica" entre cada um dos setores de pesquisa.

Já sob uma perspectiva da História do Direito, Costa afirma que seu desenvolvimento fulcral é a partir da figura de Savigny, que criou a imagem do historiador do direito. Os trabalhos de Savigny, conforme registra Costa (2010, p. 28-32), identificavam e buscavam a continuidade de uma tradição. Assim, sua teoria reforçava a ideia de unidade de um sistema jurídico, por meio de uma harmonia entre história e teoria jurídica. A conclusão de Savigny foi que a dogmática servia de atualização, criação e manutenção do direito; devendo o historiador do direito, portanto, refletir a partir da tensão entre o dogma e a história.

Posteriormente, conforme o jurista italiano Emillio Betti reafirma a premissa teórica de Savigny, na medida que tende (apud QUINAUD PEDRON, 2012, p 61-62):

[...] a resolver a especificidade da história do direito dando importância central ao elemento jurídico: a história não sai, nesta perspectiva, do círculo mágico do direito. Na unidade e na continuidade da tradição, no perfeito espalhar-se do ordenamento do saber, a experiência jurídica se perfilava como uma zona perfeitamente concluída e definida que o historiador contemplava através do filtro obrigatório da dogmática de seu presente.

Não obstante, também adverte Pietro Costa (2010, p. 62):

[...] o problema comum, ao historiador do direito como a qualquer outro historiador, é compreender que coisa diz o texto e como o texto diz aquilo que diz”. É nesse ponto que se destaca a basilar necessidade de o historiador do direito ter conhecimento da natureza da juridicidade que analisa, uma vez que "o intérprete atribui um significado ao texto e nos conta o texto, constrói uma narrativa através do texto e sobre o texto; esta narrativa tem uma coerência e intangibilidade na medida em que fala de alguma coisa, na medida em que tem um tema e coordena os próprios enunciados em torno a ele, se o tema em questão é definível como jurídico em qualquer significado que esta expressão possa assumir no nosso hodierno léxico teórico, a narrativa pode dizer-se uma narrativa histórico-jurídica. 
Nesse diapasão, torna-se claro o papel de tradução do historiador, quiçá do investigador do Direito diante de sua narrativa jurídica, seja ela zetética ou dogmática.

Diante do exposto, passa-se agora a analisar os métodos propostos por Reinhart Koselleck, de modo que possamos avaliar se a proposta metodológica se revele ferramenta útil para o filtro dogmático ou zetético de um trabalho histórico, bem como se pode costurar o diálogo entre a natureza de juridicidade de um objeto de estudo ao texto científico.

\title{
2.3 A Histórica de Koselleck: A Concepção e Reflexo do "Tempo Histórico" na pesquisa da História
}

Nesta primeira proposta koselleckiana, impõe-se a análise da tensão da alteridade entre passado e presente, premissa que reflete no ponto de partida dessa historiografia, denominada de tempo histórico que, assim como o "Dasein" heideggeriano, está essencialmente preocupado com a finitude e a temporalização da experiência humana.

Definindo a histórica de Koselleck, em breves palavras, Costa (2010, p. 51) atribui que:

\begin{abstract}
[...] a atenção de Koselleck ao relacionamento entre discursos e práticas está diretamente conectada com a intenção de fornecer uma compreensão estritamente histórica dos conceitos políticos. Os conceitos políticos encontram seu húmus em um contexto especifico, e o contexto em que tais conceitos devem ser situados, segundo Koselleck, é não apenas a textura discursiva de uma situação histórica, seu discurso público ou debate, mas a realidade histórica como um todo: a ideia de Koselleck de "contexto" traz À mente a ideia de um "contexto situacional" [...], no qual não apenas palavras e discursos, mas até mesmo práticas não formuladas verbalmente, ações e comportamento estão incluídos.
\end{abstract}

Nessa senda, extrai-se dessa metodologia, que há uma simultaneidade de tempos históricos, subdivididos em extratos do tempo que, por seu turno, vinculam a unidades políticas e sociais da ação humana.

Assim, para apreender esses tempos históricos e, por conseguinte, ter conhecimento do passado, Koselleck apresenta duas alternativas: (a) investigando situações que podem e foram articuladas de uma maneira linguística, o que lhe permite uma análise das fontes históricas; ou (b) reconstruindo o que não articulado pela linguagem, mas que, por vestígios históricos, podem ser levantados e sustentados na forma de hipóteses e métodos. 
Como solução do problema da historiografia como produtora de conhecimentos objetivos, Koselleck propõe o estudo da Histórica (Historik), como uma metateoria da historiografia, que analisa e explica as suas próprias condições de possibilidade de existência. Assim, apresenta como possível de ser teorizado o "Dasein" Heindegariano a partir da análise de pares antitéticos de determinadas categorias, ilustrando o par "amigo e inimigo", "senhorio e servidão", entre outros.

Na mesma linha, Koselleck apresenta o seu mais importante par estudado: "horizonte de expectativa" e "espaço de experiência", o qual definirá o "ser" da dimensão da temporalidade.

Por experiência, Koselleck designa um "passado presente" que incorpora e permite que acontecimentos possam ser recordados. Essa experiência não é apenas racional, mas traz em si modos inconscientes de comportamento que não deveriam estar ainda presentes nessa forma de saber. Além disso, sua transmissão faz com que ela se aliene tornando-se uma experiência alheia. Já a expectativa, traz o hoje ou um futuro presente como traço fundamental; se volta aquilo que ainda não foi objeto da experiência, o que ainda deve ser descoberto. Inclui a esperança/temor, desejo/vontade, inquietação/análise racional, visão receptiva/curiosidade" (QUINAUD PEDRON, 2012, p. 69).

É por conta dessa crucial tensão desse par antitético - onde se entrecruzam passado, presente e futuro - que se desenvolve o tempo histórico de Koselleck.

No entanto, ainda não satisfeito, Koselleck apresenta duas metas para a compreensão fecunda do tempo histórico: “1) esboçar a dimensão meta-histórica e, com isso, demonstrar como a experiência e a expectativa - como dados antropológicos prévios - são condições da história possível, e 2) mostrar historicamente como a coordenação entre experiência e expectativa se move e se modifica no transcurso da história".

Ademais, é curioso ressaltar que a proposta de Koselleck indica que "o que se espera do futuro estará limitada pelo que se sabe do passado". Com esse raciocínio, Koselleck observa que com o advento do iluminismo, houve um aceleramento nas relações temporais, na medida que urgia, de modo preeminente, a transformação política, social e econômica do mundo. Com isso, oportuno observar que, a proposta kosseleckiana afirma que a Modernidade se caracteriza por um momento histórico no qual a expectativa distancia cada vez mais das experiências pretéritas (QUINAUD PEDRON, 2012, p. 71). 
Ademais, Koselleck busca compreender o futuro concebido pelas gerações passadas, para tanto, reflete sobre a transformação conceitual da história na modernidade. Assim, a História se assume, a grosso modo, como um conjunto de experiências. A História até o século XVIII tem como característica o quadro de exemplo para instruir uma sociedade e os grupos sociais. Discorre-se, assim, para o efeito da História como "Magistra vitae"33 (KOSELLECK, 2006, p. 21-41).

Notamos assim, que a História, mestra da vida, associa em si as esferas política, social e temporal. A História, como conjunto de experiências, serve para os homens do século XVIII como uma forma de ensinamento, que os torna mais "sábios" para prever e determinar as causas e acontecimentos na História. No entanto, com o advento da Modernidade, Koselleck observa a ruptura no modelo da História Magistra vitae, caracterizada pelas narrativas, ou seja, pertinente ao campo da Historie (Ibid, p. 40 - 44).

Assim, analisando a atmosfera alemã o autor argumenta para a renovação da definição da História - Historie - para a "História em sim" - Geschichte. Nas palavras de Koselleck: “A história adquire então uma nova dimensão que escapa à narratividade dos relatos, ao mesmo tempo em que se torna impossível capturá-la nas afirmações que se fazem sobre ela." (KOSELLECK, 2006, p. 49)

A nova definição de História, esboçada na historiografia alemã, segundo Koselleck, abandona a exclusividade da narrativa, solapando as concepções de acúmulo de experiência dos “oráculos” da História.

Nesse novo quadro de vocábulos históricos a Geschichte se fundamenta da seguinte forma: da pura narrativa factual a representação dos fatos históricos, a Geschichte configura-se para o historiador como uma exigência do reconhecimento das fontes históricas, a crítica documental, assim como o estabelecimento de uma metodologia da Histórica capaz de lidar com os fatos ocultos e internos dos acontecimentos. Da renovação da concepção da História e Tempo, transformaram-se dois conceitos muito caros ao trabalho do historiador, isto é, a visão de progresso e revolução. Até antes da modernidade, era comum a idéia de naturalização dos eventos históricos. O tempo seguia grosso modo um desencadeamento natural, vinculado à idéia de natureza. No entanto, Koselleck argumenta que a partir da Modernidade a relação de naturalização e temporalização começa a ser questionada, quando as previsões começam a não se concluir. Dos intercursos entre prognóstico e diagnóstico em relação às previsões históricas, o autor identifica a formulação de uma teoria do progresso (Ibid, p. 31-39).

3 Na tradução do latim: "Mestra da vida", termo imortalizado pelo orador romano Marcus Tullius Cicero, diante da célebre frase: "Historia vero testis temporum, lux veritatis, vita memoriae, magistra vitae, nuntia vetustatis" (A história é testemunha do passado, luz da verdade, vida da memória, mestra da vida, anunciadora dos tempos antigos). 
Sem embargo, Koselleck afirmava que esse progresso estava fundado na aceleração do tempo, o qual objetivava a consolidação de um projeto de modernidade e, ao mesmo tempo, lançava a humanidade para o desconhecido, nas suas próprias palavras:

\begin{abstract}
Se o futuro da história moderna abre-se para o desconhecido e, ao mesmo tempo, torna-se planejável, então ele tem de ser planejado. A cada plano, introduz-se um novo elemento que não pode ser objeto da experiência. $\mathrm{O}$ aspecto arbitrário da história cresce paralelamente a sua capacidade de realização. Um sustenta a outra e vice-versa. Ambos compartilham da destruição do espaço, a qual, até então, parecia ser determinado a partir do passado.
\end{abstract}

Ainda, Koselleck indica que não somente a transformação conceitual da história, como o pensamento da idade moderna ficou marcado em razão de uma peculiar aceleração. A ideia de aceleração do tempo consiste na formulação de um futuro no qual as gerações passadas o concebem ou definem, modificando diversos conceitos históricos, principalmente a própria definição da História e o tempo histórico. (Ibid, p. 22)

Nesse norte, exemplifica o quanto a estrutura temporal foi alterada no período setecentista, citando o famoso discurso de Robespierre sobre a Constituição revolucionária: "É chegada a hora de conclamar cada um para o seu verdadeiro destino. O progresso da razão humana preparou esta grande revolução, e vós sois aqueles que recai o especial dever de acelerá-la” (KOSELLECK, 2006, p. 26).

Para ele, o progresso influencia a adoção de uma nova dinâmica de tempo. Nas palavras do autor: "Assim, o progresso descortina um futuro capaz de ultrapassar o espaço do tempo e da experiência tradicional, natural e prognosticável, o qual, por força de sua dinâmica, provoca por sua vez novos prognósticos, transnaturais e de longo prazo" (Ibid, p. 35-36).

Desse modo, oportuno registrar a conclusão tecida por Flávio Quinaud Pedron (2012, p. 71-72) ao referir sobre a proposta de tempo histórico atribuído por Koselleck:

\footnotetext{
Com sua proposta teórica, Koselleck apresenta uma nova formação de pensar a historiografia, ancorada em uma dimensão de um estudo objetivo do passado. Assim, acaba por desenvolver um método histórico, com implicações críticas. À luz desse raciocínio, o autor pôde demostrar como a classificação dos conceitos sociais e políticos, segundo as categorias da experiência e da expectativa, podem oferecer uma chave interpretativa capaz de mostrar como o tempo histórico sofre a sua modificação. Essa proposta teórica abre as portas para pensar outra forma de metodologia para o estudo da história, que Koselleck chamará de "História dos Conceitos" [...]".
} 


\subsection{A História dos Conceitos: O Método de Investigação Semântica e Aplicação de um Conceito}

Nesta proposta metodológica, Reinhart Koselleck aponta questões de ordem teórica sobre a história conceitual do pensamento político e social (Begrisffsgeschichte).

Assim, Koselleck propõem o estudo na perspectiva de seis pontos, quais sejam: $1^{\circ}$ ) $\mathrm{O}$ que possa vir a ser um conceito a respeito do qual poder-se-ia conceber uma história; $2^{\circ}$ ) Como utilizar e empregar os conceitos; $3^{\circ}$ ) Quais são os critérios seletivos quando se pensa na escrita de uma história dos conceitos; $4^{\circ}$ ) Qual é o momento do pensamento e do discurso de um conceito; $5^{\circ}$ ) Como mensurar a força diacrônica que se pretende trabalhar; $6^{\circ}$ ) - Separação analítica linguística: acomodação da realidade à mesma linguagem.

\subsection{1 - A matriz da concepção da História de um Conceito}

Primeiramente, Koselleck (1992, p. 132-135) afirma que não são todas as palavras que permitem se transformarem em conceitos, exemplificando que as expressões: “oh!”, “Ah!” e a preposição “e”, são palavras inaptas para constituírem uma história dos conceitos.

No entanto, palavras como Estado, Revolução, História, Classe, Ordem ou Sociedade comportam a possibilidade associação a um mínimo de sentido comum (minimal Bedeutungsgehalt), sendo palavras importantes e significativas, aptas, portanto, a história dos conceitos (KOSELLECK, 1992, p. 135).

Com efeito, Koseleck (Ibid, p. 136) sustenta que por meio de uma história dos conceitos é possível "indicar a partir de quando um conceito tronou-se fruto de uma teorização e quanto tempo levou para que isso acontecesse". Segundo o autor, esse problema é possível de ser empiricamente resolvido, diante do trabalho com as fontes.

\subsubsection{Como utilizar e empregar um conceito}

Koselleck (1992, p. 136) defende que todo conceito é sempre concomitantemente Fato e Indicador, uma vez que é não apenas efetivo enquanto fenômeno linguístico, mas também indicativo de algo que se situa no campo extralinguístico. Assim, é possível expressar a tradução de que "um conceito sempre relaciona-se sempre àquilo que se quer compreender, sendo portanto a relação entre o conceito e o conteúdo a ser compreendido, ou tomado inteligível, uma relação necessariamente tensa”. 
Nessa moldura, é importante a reflexão sobre a utilização e emprego dos conceitos, já que para Koselleck (Ibid, p. 136), toda postura que reduz a história a um fenômeno de linguagem é errônea, justificando que, casso adotado tal premissa, seria assumido que o trabalho do historiador se localiza no puro campo da hermenêutica.

\subsubsection{Quais são os critérios seletivos quando se pensa na escrita de uma história dos conceitos}

Neste ponto, sugere-se que o conceito deve se articular a um certo contexto, a partir de uma análise texto/contexto na sua acepção mais reduzida: "o parágrafo no conjunto de um texto maior”. Nas palavras do autor (KOSELLECK, 1992, p. 136-137):

\footnotetext{
"Um desdobramento lógico desse procedimento exige necessariamente a contextualização dos termos em unidades maiores, num conjunto de textos, por exemplo, como livros, panfletos ou manifesto, cartas, jornais etc. Por sua vez, esse texto maior, no qual o termo insere, articula-se a um contexto ainda mais ampliado para além do próprio texto escrito ou falado. O que significa dizer que todo conceito está imbricado em um emaranhado de perguntas e respostas, textos/contextos".
}

Ademais, Koselleck (Ibid, p. 137) registra que a história dos conceitos também deve ser pensada a partir de um procedimento metodológico, que denomina de "seleção" (Ausgrenzung) do que é pertinente ou não a um conceito. Nesta conjectura, conclui que:

[...] tanto poderei proceder à análise dos conceitos a partir de um método que privilegiaria textos comparáveis, quanto poderei proceder metodologicamente expandido minha análise ao conjunto da língua. Entre esses dois procedimentos haveria ainda formas intermediárias. $\mathrm{O}$ objeto se mantém o mesmo, e o que se altera é apenas a perspectiva em relação a ele.

\subsubsection{Qual é o momento do pensamento e do discurso de um conceito}

Quanto a este ponto, Koselleck (Ibid, p. 138) problematiza e reflete sobre a seguinte hipótese: "todo conceito só pode enquanto tal ser pensado e falado/expressado uma única vez. O que significa dizer que sua formulação teórica/abstrata relaciona-se a uma situação concreta que é única".

Este caráter único e particular (Einmaliqkeit) configura o momento concreto em que o conceito é formulado e articulado, tornando possível forjar da mesma palavra um novo conceito, sendo único em uma nova situação histórica. 
Koselleck (Ibid, p. 140-141) ainda argumenta sobre a importância da semântica e do uso pragmático da linguagem na lógica da história dos conceitos. Assim, registra que o uso pragmático da linguagem é sempre único e irreptível. No entanto, é imprescindível o domínio da semântica para compreensão da comunicação linguística e para o próprio uso pragmático da língua. Nesse diapasão, afirma que a semântica, invariavelmente, deve ser repetível, porquanto o seu conteúdo só pode ser compreendido se houver pressuposto um mínimo de repetição. Destarte, conclui (KOSELLECK, p. 140) seu pensamento no sentido de que:

\begin{abstract}
[...] devemos partir teoricamente da possibilidade de que em cada uso pragmático da linguagem (Sprachpragmatik), que é sempre sincrônico, e relativo a uma situação específica, esteja contida também uma diacronia. Toda sincronia contém uma diacronia presente na semântica, indicando temporalidades diversas que não posso alterar. E aqui situa-se o ponto que pode sustentar a minha defesa de uma história dos conceitos: ela pode ser escrita, posto que em cada utilização específica (situative Verwendung) de um conceito, estão contidas forças diacrônicas sobre as quais eu não tenho nenhum poder que se expressam pela semântica. As mudanças neste campo são muito lentas do que no campo do uso pragmático da língua.
\end{abstract}

\title{
2.4.5 Como mensurar a força diacrônica que se pretende trabalhar
}

Depois de considerado que a diacronia está contida sincronia, questiona-se como mensurar a força diacrônica, quando se pretende trabalhar empiricamente.

Como resposta, apresenta metodologia utilizada na sua obra "Dicionários de Conceitos", onde concebeu três grupos de fontes e buscou para sintonizar as estruturas temporais desses textos, "no sentido de apreender quando estruturas repetitivas poderiam indicar forças diacrônicas e quando, por outro lado, um uso único da língua não deixaria pensar numa semântica que se repetiria” (Ibid, p. 143).

O primeiro grupo de fontes se trata da linguagem do cotidiano, que são únicas por principio, denominando-as de fontes primárias, "que do ponto de vista de sua estrutura se articularia ao cotidiano, e cujo sentido primeiro é uma leitura única”. Quanto ao segundo grupo de fontes poderia ser analisado nos dicionários e enciclopédias, comparativamente, de modo que se possa constatar quando na língua o conceito se transforma, ganhando outro valor (Ibid, p. 143-144).

Por fim a terceira fonte, passível de mensurar uma força diacrônica, o qual concerne aos textos inalterados, ainda que decorrentes de sucessivas edições: "é o caso por exemplo da obra de Kant, do texto bíblico, da obra poética, enfim aplica-se aos chamados textos clássicos dos diferentes campos do saber" (Ibid, p. 144). 
Desse modo, compreende-se que por meio da análise dos três grupos de fontes, é possível observar que as estruturas repetitivas encontram-se, diferentemente, distribuídas. Assim, assinala-se que a semântica comporta em si estruturas de repetição, mas a semântica mesma, de acordo com o gênero e o tipo de texto, possibilitará, impedirá ou mesmo proibirá diferentes formas de repetição.

\subsubsection{Separação analítica linguística: acomodação da realidade a mesma linguagem.}

Veja que até então, a proposta de aplicação metodológica Koselleckiana verifica que a modificação dos conceitos muito se passa diante da pluralidade de atores históricos e de suas advindas ações, bem como pelo esquecimento das experiências anteriores. Diante disso é que se tem fundamental a aplicação do método da História do Conceito, já que por meio dela é possível observar o quadro transformativo ou de continuidade das estruturas da realidade, possibilitando, por conseguinte, uma leitura crítica do uso dos conceitos. Neste sentido, Koselleck (1992, p. 145) sentencia que:

[...] uma história dos conceitos só é possível de ser pensada sob a premissa teórica de que se realize uma separação analítica entre Sprachausage e Sachanalyse quando se quer ter clareza acerca do que se fala. A separação analítica entre cada afirmação linguística presente em todas as fontes textuais e a história concreta, o que deveria ser ou supostamente é, deve ser obrigatoriamente realizada de forma rigorosa do ponto de vista teórico. Só então posso perguntar às fontes textuais o que elas indiciam em relação à história concreta e que qualidades possuiriam para coproduzirem história enquanto textos.

Nesse mesmo sentido, Luísa Rauter Pereira (apud QUINAUD PEDRON, p. 72)

declara que a história dos conceitos desenvolve:

[...] uma semântica dos conceitos históricos que busque a constituição linguística de experiências do tempo na realidade passada. A ciência histórica deve se referir ao problema da experiência histórica, com suas diferentes "ontologias" sociais do tempo", que indicam e informam "tensões existenciais" relativas à finitude humana. Atentando para estes elementos existenciais, a história pode chegar a entender os conflitos políticos e sociais que caracterizam os diversos períodos históricos. 
Ademais, acerca da pertinência desta proposta metodológica, também se faz o registro de Luísa Rauter Pereira (apud QUINAUD PEDRON, p. 73), ao afirmar que:

\begin{abstract}
[...] os conceitos históricos com que se depara o historiador em seu trabalho possuem um duplo caráter. Por um lado, expressam conteúdos de experiências, conjunturas, modos de pensar já sedimentados. Por outro, são projeções, visualizações de um futuro possível, projetos e prognósticos. Em outras palavras são índices de realidade e fatores de mudança social."
\end{abstract}

Não obstante, é possível constatar que a "begriffsgechichte" de Koselleck também demonstra ser um movimento de superação da história das ideias, porquanto defenda a existência objetiva das ideias e conceito, estáveis e não passíveis de tradução (Ibid, p. 73)

Sem embargo, nesse período de revisão metodológica, também surgem as figuras de Pocock e Skinner, que contribuem a crítica revisional dos métodos de interpretação e análise da história. Ambos são expoentes da denominada Escola de Cambridge, ou Escola Contextualista, que propôs uma nova abordagem de interpretação dos discursos de pensadores do passado, a fim de evitar projeções de falsas afirmações e expectativas.

Ainda, sobre a onda revisional metodológica do século XX, Marcelo Jasmin (2005, p. 28) preceitua que:

[...] a partir desse programa básico, uma sofisticada elaboração metodológica e conceitual acerca do fazer história das ideias (ou dos discursos, dos atos de fala, da linguagem política e social etc.), das noções de significado e de intenção e dos limites da historiografia do pensamento político e social, assim como uma pujante produção historiográfica com frequência identificada com o rótulo "escola de Cambridge" e com a coleção "ideas in Context", se desenvolveram, provocando reações diversas que constituíram um profícuo debate metodológico internacional entre historiadores, filósofos, cientistas políticos e críticos literários.

É nessa mesma atenção metodológica que surge as principais teorias de Koselleck, logo após a metade do século XX, o qual, segundo T. B. Kirschner (apud QUINAUD PEDRON, p. 76):

[...] chama a atenção para importância da análise linguística e semântica da investigação das variadas dimensões do mundo social em diferentes época. Segundo o autor, o estudo dos conceitos e da variação dos seus significados ao longo do tempo é uma condição básica para o conhecimento histórico. Koselleck denomina História dos Conceitos o procedimento que permite apreender o complexo processo de ressignificações de alguns conceitos ao longo do tempo. Mais do que um método a ser aplicado ou uma disciplina autônoma, a História dos Conceitos seria um instrumento complementar e necessário para a interpretação história. 
Nesse norte, a história dos conceitos, tal como proposta por Koselleck, demonstra ser um método eficiente e muito interessante na investigação histórica, sobretudo no período pós liberal, na medida que não assenta seus fundamentos em apenas compreender aos "estratos semântico dos textos, mas também às descontinuidades das estruturas e contextos sociais de sua produção" (QUINAUD PEDRON, 2012, p. 77).

\section{A APLICAÇÃo METODOLÓGICA KOSELLECKIANA NAS PESQUISAS JURÍDICAS}

Não é demais ressaltar que é por meio e somente pela investigação criteriosa, ou seja, na investigação amparada em métodos adequados, que se tem a descoberta científica. Assim, é da ligação entre o nihil e o produto inventivo que se encontra a realização acadêmica. Como ressaltam Bruyne, Herman e Schoutheete (apud BITTAR, 2011, p. 23):

O contexto da descoberta é aquele no qual nos perguntamos como encontramos, como construímos nossas hipóteses e nossas teorias; eis aí, evidentemente, um contexto que a reflexão metodológica não pode deixar de lado sem se condenar a um formalismo pouco compatível com a função heurística que toda metodologia consequente deve promover.

Nesse diapasão, Bittar (Ibid, p. 25) afirma que:

Se as ideias se sucedem num processo indefinido de criações cientificas, a metodologia representa a escora para manipulação delas, porque a ciência desprovida de cuidados metodológicos cederia ao primeiro impulso contestatório que viesse a sofrer; a ciência deve ser um saber sustentável, comprovado em suas aquisições e formulações. Se suas teses se substituem, e são instáveis, o método é o elemento mínimo de escora, segurança e estabilidade das teses científicas.

Quanto ao meio de se atingir a reflexão metodológica, Bruyne, Herman e Schoutheete afirmam que a pesquisa deve apresentar a maior gama possível de procedimentos epistemológicos, teóricos, morfológicos e técnicos, a fim de produzir um resultado acadêmico fecundo.

No entanto, oportuno ressaltar que o resultado da pesquisa jamais será eterno por si só, pois como adverte Popper (apud BITTAR, 2011, p. 25):

A exigência de objetividade científica torna inevitável que todo o enunciado científico permaneça provisório para sempre. Pode ele, é claro, ser corroborado, mas toda corroboração é feita com referência a outros enunciados, por sua vez provisórios. Apenas em nossas experiências subjetivas de convicção, em nossa fé subjetiva, podemos estar absolutamente certos. 
Sem embargo, Bittar (2011, p. 65) adverte que a Ciência Jurídica é normativa e aplicada. Desse modo, não se preocupa propriamente de fenômenos naturalísticos, mas sim valorativos, sendo este o cerne do debate jurídico.

Ainda nesse vértice, Bittar (Ibid, p. 66) critica o segmento ortodoxo acadêmico por uma "Teoria pura do Direito", tal como postulado por Kelsen, uma vez que ao retirar todo o conteúdo dito metajurídico no estudo do Direito, empobrece a argumentação, fundamentação e análise dos objetos perquiridos na investigação científica.

É diante dessa tônica que observamos a pertinência da aplicabilidade das matrizes metodológicas propostos por Koselleck, tanto em áreas jurídicas características da dogmática (Direito Constitucional, Direito Penal, Direito do Trabalho...), como da Zetética (Filosofia do Direito, Sociologia Jurídica, Antropologia do Direito e, principalmente, História do Direito).

Quando se emprega a denominação da área de concentração jurídica dogmática, tem-se melhor aquela classificada e conceituada por Eduardo Bittar (Ibid, p. 86-87), no sentido de que:

\begin{abstract}
De fato cumprindo seu papel científico, a dogmática apresenta respostas, eliminando, com isso, a polissemia, definindo contornos, ordenando pensamentos, classificando, concatenando, impondo à variabilidade certa conotação de durabilidade. É nítido que assim age com vistas à decidibilidade, sobressaindo o aspecto resposta na apresentação e definição de problemas. A dogmática jurídica se apresenta, aqui, como ciência de mediação entre a pura prática textual aplicativa e as referências textuais normativas que figuram em sua generalidade, propondo-se, para tanto à elaboração de juízos de interpretação e sistematização coerentes das máximas jurídicas vigentes.
\end{abstract}

Veja que, na área de concentração dogmática, não é somente primordial solucionar problemas jurídicos, mas também eliminar a plurissignificação de conceitos, ordenar pensamentos, classificá-los e concatená-los, de modo que se imprima "certa conotação de durabilidade". E é nesse norte que a metodologia koselleckiana se demonstra uma ferramenta útil nessas modelos de pesquisa, principalmente através da sua História Conceitual, já que permite desempenhar o alvitre dogmático de rotulação de conceitos e, por conseguinte, de seus objetos jurídicos investigados.

Nessa moldura, oportuno ilustrar, como referencial à aplicação metodológica koselleckiana na pesquisa dogmática jurídica, a obra intitulada "Mutação Constitucional na Crise do Positivismo Jurídico: História e Crítica do Conceito no Marco do Direito como Integridade”, de Flávio Quinaud Pedron. Nessa obra, Quinaud Pedron (2012, p. 07-52) critica o posicionamento conferido pelo Supremo Tribunal Federal, ao distorcer o instrumento de mudança constitucional denominado de Mutação Constitucional. Nesse diapasão, para 
comprovar sua tese, de que aquela espécie de vicissitude constitucional estava sendo distorcida pelo Tribunal Constitucional, propôs revisar o conceito histórico de mutação constitucional. Com efeito, Quinaud Pedron (Ibid, p. 81) faz uso da lição de Reinhart Koselleck, pois, nas suas palavras:

\begin{abstract}
[...] o desenvolvimento metodológico trazido por Koselleck pode ser importante para repensar a própria mutação constitucional. Uma importante observação é a de que os autores nacionais (NERY JR., PEDRA, VECHI, BULOS, FERRAZ), ao produzirem pesquisa sobre o tema, limitaram-se a realizar um corte histórico ainda preso a uma história das ideias, o que representa uma perda substancial para a leitura do fenômeno, já que o estudo da mutação constitucional é tratado sem consciência dos processos de continuidade e descontinuidade ao longo dos diversos contextos históricos em que é empregado. Nesse sentido, uma teoria da mutação constitucional pode ser realizada atrás do fio condutor da construção de Koselleck. Ela é um conceito que, no interior do progresso histórico, representando pelas constantes e revolucionárias mudanças no cenário e no discurso político-jurídico, irá assumir diversas leituras, mantendo um denominador comum: a ideia de um descompasso entre norma e realidade. A norma, aqui assumindo o conjunto positivado de uma constelação de vivências e experiências, passa a se distanciar cada vez mais de uma realidade cambiante, que, por sua vez, é provedora de expectativas sociais.
\end{abstract}

Assim, assume a responsabilidade de resgatar historicamente o conceito de Mutação Constitucional, com o auxílio metodológico de Reinhart Koselleck, estruturado nas seguintes premissas (Ibid, p.77):

\begin{abstract}
1) Até que ponto é comum o uso do conceito? 2) Seu sentido foi objeto de disputa? 3) Qual o espectro social de seu uso? 4) Em que contextos históricos aparece? 5) Com outros termos aparece relacionado, seja como complemento ou como oposição? 6) Por quem é utilizado, com que propósito e quem se dirige? 7) Por quanto tempo esteve em uso? 8) Qual é o valor do conceito na estrutura da linguagem política e social da época? 9) Com que outros termos se sobrepõe? 10) Converge com outros termos?
\end{abstract}

Não obstante, também vislumbra na Historike de Koselleck, um método eficaz para que o pesquisador, compreendendo as mudanças de contexto e de realidade político-sociais, possa interpretar os textos legais (Ibid, p.82):

Sob tal prisma, Koselleck irá afirmar que a interpretação de um texto jurídico - e, no caso, a interpretação da Constituição não escapará á regra - é dependente de uma tomada de consciência da sua Histórica, já que esse saber possibilitará ao intérprete compreender as mudanças de contexto e de realidade político-sociais, para poder equalizá-las e levá-las em consideração na hora de interpretar e compreender o conteúdo linguístico do texto jurídico a que está submetido. Logo, o intérprete antes de conhecer o conteúdo do texto legal, afirma Koselleck, deve conhecer a sua situação histórica - o que quer dizer, não apenas seu presente, mas também as mudanças de um passado que ainda se faz presente. 
De igual sorte, e ainda mais perfectível, o metodologia koselleckiana também é oportuna às pesquisas da zetética jurídica, especialmente por iluminar os pontos de continuidade e descontinuidade das estruturas em dado contexto social e temporal.

Sobre a continuidade ou descontinuidade de tais estruturas, Jasmin (2005, p. 78) propõem um esquema ilustrativo que demonstra sua mutabilidade:

\begin{abstract}
Supondo que de um lado haja um estado de coisas, e de outro um conceito deste estado de coisas, quatro situações são possíveis: 1) o estado de coisas e o conceito permanecem ambos estáveis ao longo de um período de tempo, 2) o conceito e a realidade transformam-se simultaneamente; 3) os conceitos mudam sem que haja uma mudança concomitante da realidade, ou seja, a mesma realidade é conceituada de modo diverso; 4) o estado de coisas muda, mas o conceito permanece o mesmo.
\end{abstract}

Dessarte, a proposta koselleckiana permite a compreensão histórica e antropológica do progresso da modernidade, reconhecendo a (des)continuidade das estruturas em determinado contexto social e temporal, dado muito importante para as pesquisas jurídicas da área zetética, sobretudo a da disciplina de História do Direito.

\title{
4. CONCLUSÃO
}

Diante do exposto, conclui-se que o emprego metodológico Koselleckiano pode se revelar muito fértil na pesquisa jurídica, seja qual for o campo de concentração de conhecimento - dogmático ou zetético.

Não obstante, também verifica-se que não há óbice a aplicação dessa proposta metodológica em áreas que não sejam, propriamente, históricas, uma vez que os métodos aqui estudados demonstram uma grandiosa utilidade para a classificação, ordenação e distinções de categorias alvos da investigação acadêmica, bem como aporte teórico na compreensão histórica e antropológica do progresso da modernidade.

Igualmente, constata-se que o conhecimento e aplicação dos supracitados métodos à pesquisa jurídica, reflete na atual perspectiva assumida pelas Academias Jurídicas no Brasil, que é assumir a interdisciplinaridade na investigação científica, como forma de se obter um resultado de qualidade, fomentando, assim, a abertura de novos horizontes da compreensão do Direito. 


\section{REFERÊNCIAS}

BETTI, Emilio. Teoria Generale dela Interpretazione. In: QUINAUD PEDRON, Flávio. Mutação Constitucional na Crise do Positivismo Jurídico: História e Crítica do Conceito no Marco da Teoria do Direito como Integridade. Belo Horizonte: Editorial Arraes, 2012.

BITTAR, Eduardo C. B. Metodologia da pesquisa jurídica: teoria e prática da monografia nos cursos de direito. $9^{\mathrm{a}}$ ed. São Paulo: Saraiva, 2011.

BRUYNE, Paul de; HERMAN, Jacques; SCHOUTHEETE, Marc de. Dinâmica da pesquisa em ciências sociais. In: BITTAR, Eduardo C. B. Metodologia da pesquisa jurídica: teoria e prática da monografia nos cursos de direito. $9^{a}$ ed. São Paulo: Saraiva, 2011.

COSTA, Pietro. Em busca de textos jurídicos: Quais textos para qual historiador? Tradução de Walter Guandalini Jr. In: COSTA, Pietro. Soberania, representação, democracia: ensaios de história do pensamento jurídico. Curitiba: Juruá, 2010. [Biblioteca de história do direito], pp. $17-28$.

Pra que serve a História do Direito? Um humilde elogio da inutilidade. Tradução de Ricardo Marcelo Fonseca. In: COSTA, Pietro. Soberania, Representação, democracia: ensaios de história do pensamento jurídico. Curitiba: Juruá, 2010. [Biblioteca de história do direito], pp. 63-78.

D'ONOFRIO, Salvatore. Metodologia do trabalho intelectual. In: BITTAR, Eduardo C. B. Metodologia da pesquisa jurídica: teoria e prática da monografia nos cursos de direito. $9^{\mathrm{a}}$ ed. São Paulo: Saraiva, 2011.

DEMO, Pedro. Introdução à metodologia da ciência. In: BITTAR, Eduardo C. B. Metodologia da pesquisa jurídica: teoria e prática da monografia nos cursos de direito. $9^{a}$ ed. São Paulo: Saraiva, 2011.

JASMIN, Marcelo Gantus. Historia dos Conceitos e Teoria Política Social: Referências Preliminares. In: RBC. Vol. 20. n. 57, fevereiro de 2005, p. 27-38.

JOLIVET, Régis. Curso de filosofia. In: BITTAR, Eduardo C. B. Metodologia da pesquisa jurídica: teoria e prática da monografia nos cursos de direito. 9ª ed. São Paulo: Saraiva, 2011.

KOSELLECK, Reinhart. Futuro Passado: Contribuições à semântica dos tempos históricos. Tradução de Wilma Patrícia Maas e Carlos Alberto Pereira. Rio de Janeiro : Contraponto, 2006, pp 01-94.

KOSELLECK, Reinhart. Uma história dos conceitos: problemas teóricos e práticos. Estudos Históricos, Rio de Janeiro, vol. 5, n.10, 1992, pp. 132-135.

OLSEN, Nicklas. History in the Plural: an introduction to the work of Reinhart Koselleck. Londres: Berghahn Books, 2012. 
PEREIRA, Luísa Rauter. A história e o "Diálogo que somos": A historiografia de Reinhart Koselleck e a Hermenêutica de Hans-Georg Gadamer. In: QUINAUD PEDRON, Flávio. Mutação Constitucional na Crise do Positivismo Jurídico: História e Crítica do Conceito no Marco da Teoria do Direito como Integridade. Belo Horizonte: Editorial Arraes, 2012

PINTO, Álvaro Vieira. Ciência e existência. In: BITTAR, Eduardo C. B. Metodologia da pesquisa jurídica: teoria e prática da monografia nos cursos de direito. $9^{a}$ ed. São Paulo: Saraiva, 2011.

POPPER, Karl. A lógica da pesquisa científica. In: BITTAR, Eduardo C. B. Metodologia da pesquisa jurídica: teoria e prática da monografia nos cursos de direito. $9^{a}$ ed. São Paulo: Saraiva, 2011.

QUINAUD PEDRON, Flávio. Mutação Constitucional na Crise do Positivismo Jurídico: História e Crítica do Conceito no Marco da Teoria do Direito como Integridade. Belo Horizonte: Editorial Arraes, 2012 